0191-8141(94)E0019-U

\title{
High-resolution X-ray texture goniometry
}

\author{
Ben A. van der Pluijm, Nei-Che Ho and Donald R. Peacor \\ Department of Geological Sciences, University of Michigan, 1006 C.C. Little Building, Ann Arbor, \\ MI 48109, U.S.A. \\ (Received 27 September 1993; accepted in revised form 15 January 1994)
}

\begin{abstract}
High-resolution X-ray texture goniometry (HRXTG) significantly improves peak/background ratios and allows for the determination of crystallographic preferred fabrics of small regions $\left(<1 \mathrm{~mm}^{2}\right)$ in heterogeneously deformed rocks. The basic instrument is a commercially available automated single-crystal X-ray diffractometer equipped with a Mo source. A stage for transmission mode was constructed that is driven by the original motors, so the unit is fully computer controlled. Absorption corrections are calculated, which removes the need for generally difficult to obtain empirical corrections. This, combined with equipment optimization, enables us to use small irradiated volumes of rocks with variable compositions. The advantage of HRXTG in heterogeneously deformed rocks is demonstrated in a cleaved mudstone. Analysis of $<1 \mathrm{~mm}^{2}$ areas in a $2 \mathrm{~cm}$ bed showing a gradation from micaceous sandstone to slate reveals that fabric intensity of both mica and chlorite increases significantly ( $d_{\mathrm{M}}$ from 0.64 to 1.03 and from 0.45 to 0.78 , respectively), without appreciable change in the oblate shape $\left(k_{\mathrm{M}}\right)$ of the fabric. Thus, HRXTG can record a strain state at the mm-scale of heterogeneously. deformed rocks.
\end{abstract}

\section{INTRODUCTION}

CRYSTALLOGRAPHIC-preferred orientation of minerals in deformed rocks is principally determined using three methods: universal-stage optical microscopy (e.g. Turner \& Weiss 1963); (semi-)automated optical microscopy (e.g. Price 1973, Heilbronner \& Pauli 1993); and X-ray texture goniometry (e.g. Oertel 1983, Schmid \& Casey 1986). The latter method is suitable for a wide variety of minerals (see Wenk 1985) and can provide relatively rapid determination of the orientations of a large number of grains. Standard X-ray texture goniometry (XTG) determines the average crystallographic orientation of many mineral grains over a sample area of tens of $\mathrm{mm}^{2}$. However, deformation commonly is heterogeneously distributed on this scale, and this variation can only be resolved by using smaller analysis areas. We have modified and optimized a commercially available single-crystal X-ray diffractometer for XTG, significantly reducing the size of the analysis area. In addition, we replace practically difficult empirical absorption corrections with theoretically determined values, greatly increasing the flexibility of the XTG method. This short note describes the main elements of our system, and the advantage of high-resolution XTG is shown by measurements of the preferred orientation of muscovite and chlorite in a graded slate.

\section{METHODS}

Whether $\mathrm{X}$-rays pass through the sample or not defines the transmission and reflection mode of XTG, respectively (e.g. Wenk 1985). The main limitations of the reflection mode in measurements of natural rocks are two-fold: (1) only a limited range of orientations can be measured for minerals with small Bragg angles (such as phyllosilicates); and (2) the intensity of reflected Xrays decreases rapidly (an effect called defocusing). Therefore, the transmission mode is used more commonly for the analysis of minerals with large $d$ values, and there is no defocusing effect when X-rays penetrate the sample. However, in transmission mode significant corrections for absorption are needed, as discussed following a description of the equipment.

\section{Equipment}

We constructed an X-ray pole figure device for the Enraf-Nonius CAD4 automated single-crystal diffractometer that is equipped with Mo source, allowing us to measure crystallographic preferred orientation of minerals using the transmission mode. The basic design of the stage uses the built-in motors of the standard single-crystal diffractometer, so the goniometer remains fully computer-controlled by the original CAD4 hardware. The advantages of this particular set-up over XTG using a standard powder diffractometer are: (1) the lowabsorption Mo X-ray source, as opposed to a Cu source, results in greater peak/background ratios even at high tilt angles; (2) the collimation system of the singlecrystal diffractometer configuration produces a narrow, but high intensity beam relative to standard XTG; (3) the low absorption of Mo allows the analysis of thicker samples $(200 \mu \mathrm{m})$ than other X-ray sources in transmission mode. Combined, (1), (2) and (3) permit analysis of small sample areas (less than $1 \mathrm{~mm}^{2}$ ); and (4) the single-crystal configuration requires no additional motors for XTG and is therefore easily modified and computer controlled.

Samples are prepared from $c a 200 \mu \mathrm{m}$ thin rock slabs that are polished on both sides; the slab is oriented such 


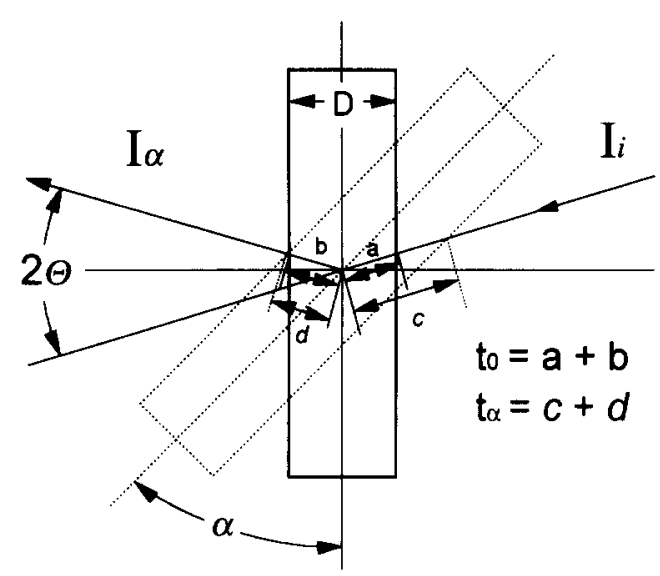

Fig. 1. Diffraction condition and change in path length during tilting in transmission mode. See text for discussion.

that the fabric element of interest is perpendicular to the cut surface. A portion of the polished slice is then attached to a $12 \mathrm{~mm}$ diameter ( $c a 100 \mathrm{~mm}^{2}$ area) aluminium sample holder for X-ray measurement; the area of interest is manually aligned with the X-ray beam. Additional X-ray fabric analyses are obtained by manually moving the sample relative to the X-ray beam. The diffractometer counter is preset to the correct diffraction angle for a given crystal plane $(h k l)$. The drive motors cause the sample to rotate over an angular sampling grid with intensity $\left(I_{h k l}\right)$ being measured at each grid point. Following corrections (see below) the data are printed out as a contoured pole figure. The orientation of the co-ordinate system of the pole figure is controlled by the operator.

\section{Corrections}

Absorption corrections for each pole figure can be obtained experimentally by measuring a polycrystalline sample having random crystal orientation and similar thickness and composition. Greater flexibility is achieved when corrections are calculated, because the preparation of standards for each phase analyzed is not necessary. Moreover, in some cases it may be nearly impossible to obtain the truly random sample that is required for empirical corrections (such as for phyllosilicates). Our derivations are based on simple trigonometry, but give the same result as the more complex integrals used in Decker et al. (1948).

When a sample rotates around the incident beam there is no change in path length or irradiated volume, but tilting of the sample relative to the incident beam (away from $90^{\circ}$ to the incident $\mathrm{X}$-ray beam) increases both the path length and the irradiated sample volume (Fig. 1). The diffracted intensity decreases with increasing path length because of absorption, but it increases with the irradiated volume. The total change in intensity is therefore a function of both of these effects.

The X-ray path length $\left(t_{\alpha}\right)$ at tilt angle $\alpha$ is calculated by:

$$
t_{\alpha}=\frac{D}{2} \times\left(\frac{1}{\cos \left(\frac{2 \theta}{2}+\alpha\right)}+\frac{1}{\cos \left(\frac{2 \theta}{2}-\alpha\right)}\right)
$$

where $D$ is the sample thickness, $2 \theta$ is Bragg's law angle of reflection, and $\alpha$ is the tilt angle. The absorption with tilt is calculated from

$$
A_{\alpha}=I_{\alpha} / I_{\mathrm{i}}=\mathrm{e}^{-\mu^{*} \rho t_{a}},
$$

where $I_{\mathrm{i}}$ and $I_{\alpha}$ are the intensity of the incident and transmitted beam, $\mu^{*}$ is the mass absorption coefficient of the sample (which is independent of the physical state of the material), $\rho$ is the density of the sample and $t_{\alpha}$ is the path length. The irradiated volume with tilt, $V_{\alpha}$, is calculated from:

$$
V_{\alpha}=\frac{D}{2} \times \frac{\delta^{2}}{\cos \left(\frac{2 \theta}{2}+\alpha\right)},
$$

where $\delta$ is the $\mathrm{X}$-ray beam diameter, $D$ is the sample thickness.

These corrections are recalculated relative to the zero tilt position. Thus at a tilt angle $\alpha, A_{\alpha} / A_{0}$ is the change due to absorption and $V_{\alpha} / V_{0}$ is the change due to the irradiated volume. The product of these two factors is the intensity change $\Delta_{\alpha}$ :

$$
\Delta_{\alpha}=A_{\alpha} / A_{0} \times V_{\alpha} / V_{0}
$$

Because of the low absorption with a Mo source, the intensity actually increases with increasing tilt (up to $c a$ $50^{\circ}$ ), as opposed to a $\mathrm{Cu}$ source where the intensity decreases. Individual intensity values are corrected using the corresponding values of $\Delta_{\alpha}$. The final values are normalized to be independent of sample parameters such as mineral content by summing all data points over the whole pole figure and weighing them with respect to their areal distribution. Intensities are then expressed as multiples of a random distribution (m.r.d.). Tilt angles as high as $50^{\circ}$ are possible, covering $80 \%$ of the pole figure area. Note that even when such a partial pole figure is obtained, normalization is still based on the whole sphere when the intensity is negligible for the area not sampled, as in our example.

There is excellent agreement between measured and calculated data for a Mo $\mathrm{K}_{\alpha} \mathrm{X}$-ray beam, for which absorption effects are small. They are readily calculated for a given sample thickness, which is measured, and for the average absorption coefficient, which varies little from sample to sample.

\section{AN APPLICATION}

Figure 2 shows pole figures for muscovite (001 reflection) and chlorite (002 reflection) for a sequence of sample points in a $2 \mathrm{~cm}$ thick fining-upward sequence in slates of the Martinsburg Formation at Lehigh Gap, Pennsylvania (sites 1-5); the corresponding principal pole densities $\left(\rho_{\mathrm{i}}\right)$ are listed in Table 1. Samples were 
Mica (001)

Chlorite (002)
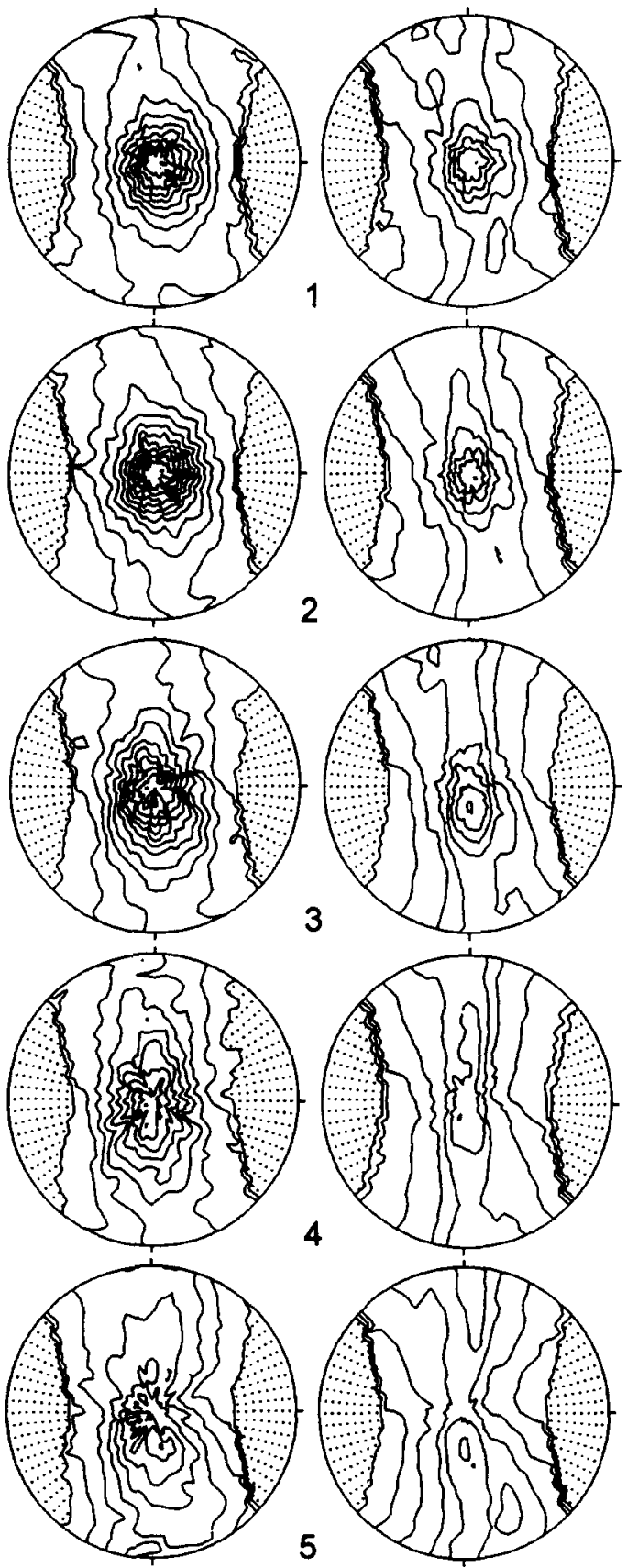

Fig. 2. Muscovite and chlorite pole figures of five sampling points in a 2 $\mathrm{cm}$ graded sequence. The maximum and lowest contour in each pole figure for mica and chlorite, respectively, are; site $1-4.57$ and 0.1 , 3.41 and 0.2 ; site $2-4.76$ and $0.3,3.45$ and 0.2 ; site $3-4.76$ and 0.3 , 3.24 and 0.4 ; site $4-3.63$ and $0.4,2.53$ and 0.1 ; site $5-3.19$ and 0.3 , 2.38 and 0.3 ; the contour interval in each figure is 0.4 . The corresponding data are listed in Table 1 and plotted in Fig. 3.

measured over an azimuthal range of $360^{\circ}$ with $2.5^{\circ}$ intervals (144 steps) and $40^{\circ}$ tilt with $5^{\circ}$ intervals (nine steps), which gives a total of 1296 measuring stations covering $70 \%$ of the pole figure area. The Lehigh gap sample was used because it is from a shale-to-slate sequence that has been well-studied using a variety of approaches (e.g. Holeywell \& Tullis 1975, Lee et al. 1986, Housen \& van der Pluijm 1991, Wintsch et al.
1991). The preferred orientations are identical for both chlorite and muscovite in all five sample points, but their intensities differ. For quantification of the preferred orientation data we use the March (1932) model that gives a numerical value of grain alignment. This allows calculation of the changes in geometry of a homogeneous, constant-volume strain that uniformly affects all components of the material. In the March model, grains are passive markers and are mechanically indistinguishable from the matrix in which they are embedded. The orientation of the markers is measured by pole figure analysis, which is quantified by relating the final pole densities in the principal directions of the March strain relative to an original uniform density (Oertel 1983):

$$
\sqrt{ } \lambda_{\mathrm{i}}=\rho_{\mathrm{i}}^{-1 / 3} \text { or } e_{\mathrm{i}}=\rho_{\mathrm{i}}^{-1 / 3}-1,
$$

where $\rho_{\mathrm{i}}$ is a principal pole density, normalized by dividing it by the average pole density for all orientations, and $V \lambda_{i}$ is the 'stretch' representing a March strain ellipsoid with axes $X, Y$ and $Z$, and $e_{\mathrm{i}}$ is the 'elongation'. The March model has been used successfully to estimate finite strains in phyllosilicate-rich rocks (e.g. Oertel 1983), but because of the assumptions inherent in the model we use the term March strain (subscript M). Characteristics of each analysis are described by the shape parameter $k_{\mathrm{M}}$, and degree of intensity parameter $d_{\mathrm{M}}$, which are defined as:

$$
\begin{aligned}
& k_{\mathrm{M}}=\left(X_{\mathrm{M}} / Y_{\mathrm{M}}-1\right) /\left(Y_{\mathrm{M}} / Z_{\mathrm{M}}-1\right) \\
& d_{\mathrm{M}}=\left(\left(X_{\mathrm{M}} / Y_{\mathrm{M}}-1\right)^{2}+\left(Y_{\mathrm{M}} / Z_{\mathrm{M}}-1\right)^{2}\right)^{1 / 2} .
\end{aligned}
$$

March strains are listed in Table 1 and they are plotted in Fig. 3. The Flinn diagram (Fig. 3) shows that March strain ellipsoids are all oblate, so their intensities may be directly compared. Results from the $2 \mathrm{~cm}$ thick layer plot over a considerable region in the Flinn diagram. Upward in the sequence (sample points 5-1) $k_{\mathrm{M}}$ values progressively decrease and $d_{\mathrm{M}}$ values progressively increase. For muscovite, $d_{\mathrm{M}}$ increases from 0.64 to 1.03 , and for chlorite $d_{M}$ increases from 0.45 to 0.78 . For each sampling site the chlorite preferred orientation fabric is significantly weaker than that for mica, reflecting a lesser degree of chlorite preferred orientation that is probably related to irregular layering on the submicroscopic scale (but exceeding the $c a 1 \mu \mathrm{m}$ resolution of Xray diffraction). Note that pole figures at the bottom of the sequence are poorly resolved (site 5 in Fig. 2) because of the large grain size, so the corresponding values of $k_{\mathrm{M}}$ and $d_{\mathrm{M}}$ have relatively large uncertainties.

The systematic progression in strain state observed in the graded slate sample can be explained in three ways (or a combination thereof): (1) increased shortening; (2) increased volume loss; and (3) increased concentration of strain in the phyllosilicates as opposed to the other phases (e.g. quartz). We prefer the third interpretation for this sample, but irrespective of the favored interpretation, these data show that high-resolution XTG is able to record variations in the strain state of deformed rocks over small, mm-scale distances. 
Table 1. Principal pole densities and March values from $\mathrm{X}$-ray texture goniometry

\begin{tabular}{|c|c|c|c|c|c|c|c|c|c|c|c|c|c|c|c|}
\hline Sample & $\rho_{1}$ & $\rho_{2}$ & $\rho_{3}$ & $e_{1}$ & $e_{2}$ & $e_{3}$ & $X$ & $Y$ & $Z$ & $\Delta$ & $X / Y$ & $Y / Z$ & $X / Z$ & $k_{\mathrm{M}}$ & $d_{\mathrm{M}}$ \\
\hline 1 chlorite & 0.48 & 0.61 & 3.41 & 0.27 & 0.18 & -0.34 & 1.27 & 1.18 & 0.66 & 1.00 & 1.08 & 1.78 & 1.92 & 0.10 & 0.78 \\
\hline 2 chlorite & 0.47 & 0.61 & 3.45 & 0.28 & 0.18 & -0.34 & 1.28 & 1.18 & 0.66 & 1.00 & 1.09 & 1.78 & 1.94 & 0.11 & 0.79 \\
\hline 3 chlorite & 0.47 & 0.65 & 3.24 & 0.28 & 0.15 & -0.32 & 1.28 & 1.15 & 0.68 & 1.00 & 1.11 & 1.71 & 1.90 & 0.16 & 0.72 \\
\hline 4 chlorite & 0.57 & 0.69 & 2.53 & 0.20 & 0.13 & -0.27 & 1.20 & 1.13 & 0.73 & 1.00 & 1.07 & 1.54 & 1.64 & 0.12 & 0.54 \\
\hline 5 chlorite & 0.49 & 0.85 & 2.38 & 0.26 & 0.06 & -0.25 & 1.26 & 1.06 & 0.75 & 1.00 & 1.20 & 1.41 & 1.69 & 0.48 & 0.45 \\
\hline 1 mica & 0.40 & 0.55 & 4.57 & 0.36 & 0.22 & -0.40 & 1.36 & 1.22 & 0.60 & 1.00 & 1.11 & 2.03 & 2.26 & 0.11 & 1.03 \\
\hline 2 mica & 0.37 & 0.56 & 4.76 & 0.39 & 0.21 & -0.41 & 1.39 & 1.21 & 0.59 & 1.00 & 1.14 & 2.04 & 2.33 & 0.14 & 1.05 \\
\hline 3 mica & 0.34 & 0.63 & 4.76 & 0.44 & 0.17 & -0.41 & 1.44 & 1.17 & 0.59 & 1.00 & 1.23 & 1.97 & 2.42 & 0.24 & 0.99 \\
\hline 4 mica & 0.38 & 0.72 & 3.63 & 0.38 & 0.11 & -0.35 & 1.38 & 1.11 & 0.65 & 1.00 & 1.24 & 1.71 & 2.12 & 0.34 & 0.75 \\
\hline 5 mica & 0.35 & 0.89 & 3.19 & 0.41 & 0.04 & -0.32 & 1.41 & 1.04 & 0.68 & 1.00 & 1.36 & 1.53 & 2.08 & 0.67 & 0.64 \\
\hline
\end{tabular}

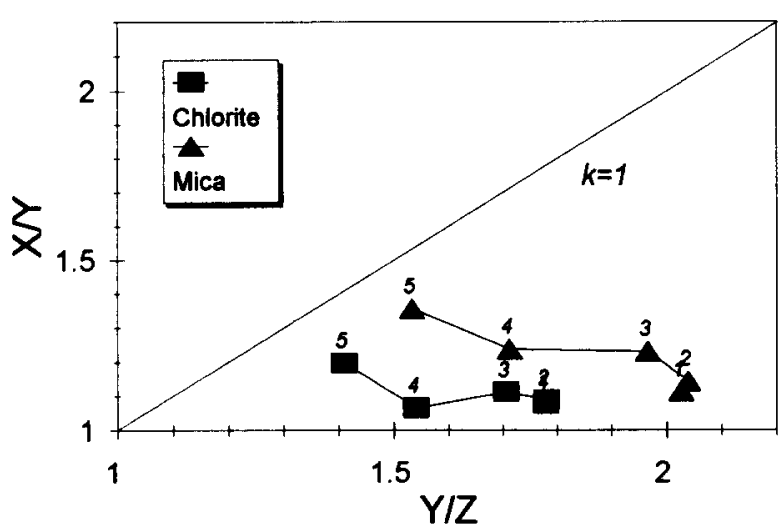

Fig. 3. Flinn plot of March strains showing increasing intensity $\left(d_{M}\right)$ and overall oblate shape of the March strain ellipsoid $\left(k_{\mathrm{M}}\right)$ for both mica and chlorite. The orientations of the muscovite and chlorite pole figures are indistinguishable for all sampling sites, but at each individual site muscovite has a higher degree of preferred orientation than chlorite.

Acknowledgements-The single-crystal diffractometer was bought under NSF grant EAR-8917350; development of the goniometer stage was supported by NSF grants EAR-9119196 (BvdP) and EAR9104565 (DRP), the Geological Society of America, and Scott Turner Fund $(\mathrm{NCH})$. Experimental data were obtained with the support of the American Chemical Society-Petroleum Research Fund (grant 27461-AC8). We are grateful to G. Oertel (UCLA) and H.-R. Wenk (UC Berkeley), who generously shared their expertise, made valuable suggestions and provided full access to their laboratories. Data processing and output of contoured plots use computer software provided by H.-R. Wenk. John Stamatakos is thanked for discussion, and Holger Stünitz and an anonymous reviewer for constructive reviews.

\section{REFERENCES}

Decker, B. F., Asp, E. T. \& Harker, D. 1948. Preferred orientation determination using a Geiger counter $\mathrm{X}$-ray diffraction goniometer. J. appl. Phys. 19, 388-392.

Heilbronner, R. P. \& Pauli, C. 1993. Integrated spatial and orientation analysis of quartz $c$-axes by computer-aided microscopy. $J$. Struct. Geol. 15, 369-382.

Holeywell, R. C. \& Tullis, T. E. 1975. Mineral reorientation and slaty cleavage in the Martinsburg Formation, Lehigh Gap, Pennsylvania. Bull. geol. Soc. Am. 86, 1296-1304.

Housen, B. A. \& van der Pluijm, B. A. 1991. Slaty cleavage development and magnetic anisotropy fabrics. J. geophys. Res. 96, 99379946.

Lee, J. H., Peacor, D. R., Lewis, D. \& Wintsch, R. P. 1986. Evidence for syntectonic crystallization for the mudstone to slate transition at Lehigh Gap, Pennsylvania. J. Struct. Geol. 8, 767-780.

March, A. 1932. Mathematische Theorie der Regelung nach der Korngestalt bei affiner Deformation. Z. Kristallogr. 81, 285-297.

Oertel, G. 1983. The relationship of strain and preferred orientation of phyllosilicate grains in rocks-a review. Tectonophysics 100, 413447.

Price, G. P. 1973. The photometric method used in microstructural analysis. Am. J. Sci. 273, 523-537.

Schmid, S. M. \& Casey, M. 1986. Complete fabric analysis of some commonly observed quartz $c$-axis patterns. In: Mineral and Rock Deformation: Laboratory Studies (Paterson volume) (edited by Hobbs, B. E. \& Heard, H. C.). Am. Geophys. Un. Geophys. Monogr. 36, 263-287.

Turner, F. J. \& Weiss, L. E. 1963. Structural Analysis of Metamorphic Tectonites. McGraw-Hill, New York.

Wenk, H.-R. (editor) 1985. Preferred Orientation in Deformed Rocks. Academic Press, Orlando.

Wintsch, R. P., Kvale, C. M. \& Kisch. H. J. 1991. Open system, constant-volume development of slaty cleavage in the Martinsburg Formation, Lehigh gap, Pennsylvania. Bull. geol. Soc. Am. 103 916-927. 